University of Texas Rio Grande Valley

ScholarWorks @ UTRGV

\title{
Patterns of childhood maltreatment and intimate partner violence, emotion dysregulation, and mental health symptoms among lesbian, gay, and bisexual emerging adults: A three-step latent class approach
}

Ruby Charak

The University of Texas Rio Grande Valley, ruby.charak@utrgv.edu

Lillianne Villarreal

The University of Texas Rio Grande Valley

Rachel M. Schmitz

Oklahoma State University

Michiyo Hirai

The University of Texas Rio Grande Valley, michiyo.hirai@utrgv.edu

Julian D. Ford

fniversity Of Connecticut wis and additional works at: https://scholarworks.utrgv.edu/psy_fac

Part of the Child Psychology Commons, and the Lesbian, Gay, Bisexual, and Transgender Studies Commons

\section{Recommended Citation}

Charak, R., Villarreal, L., Schmitz, R. M., Hirai, M., \& Ford, J. D. (2019). Patterns of childhood maltreatment and intimate partner violence, emotion dysregulation, and mental health symptoms among gay, lesbian, and bisexual emerging adults: A 3-step latent class approach. Child Abuse and Neglect, 89, 99-110. doi.10.1016/j.chiabu.2019.01.007

This Article is brought to you for free and open access by the College of Liberal Arts at ScholarWorks @ UTRGV. It has been accepted for inclusion in Psychological Science Faculty Publications and Presentations by an authorized administrator of ScholarWorks @ UTRGV. For more information, please contact justin.white@utrgv.edu, william.flores01@utrgv.edu. 


\title{
Patterns of Childhood Maltreatment and Intimate Partner Violence, Emotion
} Dysregulation, and Mental Health Symptoms Among Lesbian, Gay, and Bisexual Emerging Adults: A Three-step Latent Class Approach

\author{
Ruby Charak, Ph.D. \\ Lillianne Villarreal, B.S. \\ Department of Psychological Science, The University of Texas Rio Grande Valley, \\ Edinburg, TX. \\ Rachel M. Schmitz, Ph.D. \\ Department of Sociology, Oklahoma State University, Stillwater, OK \\ Michiyo Hirai, Ph.D. \\ Department of Psychological Science, The University of Texas Rio Grande Valley, \\ Edinburg, TX. \\ Julian D. Ford, Ph.D. \\ Department of Psychiatry, University of Connecticut Health Center
}

Corresponding author: Ruby Charak, $\mathrm{PhD}$, Assistant Professor, Department of

Psychological Science, The University of Texas, Rio Grande Valley, Edinburg, Texas.

Ph: +1-9566653733. Email: ruby.charak@utrgv.edu

Funding: This work was supported in part by a faculty development award given by the National Science Foundation (under grant HRD-1463991) to the first author. 


\begin{abstract}
Background: Childhood abuse and neglect (CAN) and intimate partner violence victimization (IPV) is prevalent among lesbian, gay, and bisexual individuals (LGB). Identification of distinct patterns of childhood and adult victimization, including technology-mediated and face-to-face IPV, and their cumulative relations to mental/behavioral health challenges, among LGB people is needed to facilitate identification of at-risk individuals.
\end{abstract}

Objective: Using latent class analysis, we first sought to identify patterns of lifetime interpersonal victimization, primarily five types of CAN and IPV in LGB emerging adults. Second, we examined if LGB-status and race/ethnicity predicted classmembership; third, we assessed differences between the latent classes on emotion dysregulation, depressive and anxiety symptoms, and alcohol use. Participants: Participants were 288 LGB adults between $18-29$ years $(M=25.35, S D=2.76 ; 41.7 \%$ gay/lesbian) recruited via Amazon MTurk.

Methods and Results: The 3-step LCA identified five-latent classes: high victimization, childhood emotional abuse and neglect, cybervictimization, adult face-to-face IPV, and lower victimization. People of color (including Hispanics) were more likely to be in the high victimization class, and bisexual individuals, especially bisexual women, in the childhood emotional abuse and neglect class. High victimization and childhood emotional abuse and neglect classes had elevated emotion dysregulation levels and depression and anxiety symptoms, and the high victimization class reported the highest levels of alcohol use. 
Conclusion: Findings suggest a detrimental effect of cumulative interpersonal victimization on emotion dysregulation and the mental/behavioral health of LGB emerging adults, with bisexuals and LGB-people of color at heightened risk of cumulative victimization and of related mental/behavioral health challenges.

Keywords. Childhood maltreatment, IPV, Cyber IPV, Lesbian, Gay, Bisexual, Emerging adults 


\section{Patterns of Childhood Maltreatment and Intimate Partner Violence, Emotion Dysregulation, and Mental Health Symptoms Among Lesbian, Gay, and Bisexual Emerging Adults: A Three-step Latent Class Approach}

Studies indicate a link between victimization during childhood and the likelihood of perpetration and/or victimization in later romantic relationships (Ehrensaft et al., 2003; Manchikanti Gomez, 2011). While a number of studies suggest that individuals who are lesbian, gay, or bisexual are at an increased risk of childhood abuse and neglect (CAN) (Sterzing et al., 2017; Sterzing, Hong, Gartner, \& Auslander, 2016), and victimization at the hands of an intimate partner (IPV) (Goldberg \& Meyer, 2013; Messinger, 2011), few have simultaneously examined the cumulative effect of CAN and IPV on mental health challenges among LGB individuals (Balsam, Rothblum, \& Beauchaine, 2005).

Further, prior studies have not considered technology-mediated intimate partner violence (e.g., via social media) among LGB emerging adults (i.e., individuals in the age range of 18-29 years) (Arnett, 2000). Given that 98\% of emerging adults in the United States (i.e., 18-29 years of age) use the Internet, and $88 \%$ use some form of social media on a daily basis, these platforms can act as venues for victimization (Zweig, Lachman, Yahner, \& Dank, 2014). The current study aims to bridge these gaps by investigating latent classes of childhood maltreatment types, and face-to-face and technology-mediated IPV, and assessing differences across latent classes in emotion dysregulation, depression and anxiety symptoms, and alcohol use in a community sample of LGB emerging adults.

The developmental stage of emerging adulthood is a stage that offers opportunities for exploring one's identity in the area of love, work, and worldviews (Arnett, 2000). Unlike dating in adolescence wherein the pursuit is shared recreation 
activities (e.g., prom, parties), in emerging adulthood the focus is more on exploring the potential for long term emotional and physical intimacy (Arnett, 2000). The stage is thus a pivotal point for examining violence patterns as also found in the National Intimate Partner and Sexual Violence Survey (NISVS) (Black et al., 2010). A sub-report from the same national survey (NISVS) (Walters, Chen, \& Breiding, 2013) examining rates of victimization among people who are lesbian, gay, or bisexual indicated that age at the time of first completed rape among bisexual women was 18-24 years old next to the stage of adolescence (i.e., $33.1 \%$ vs. $48.2 \%$ ). No other information was provided in this survey in relation to other types of IPV (e.g., psychological abuse, physical assault) among gay and lesbian individuals.

\section{Childhood Maltreatment among LGB Individuals}

A study of 125 adolescents who identified as lesbian, gay, or bisexual revealed that the prevalence of CAN ranged from $7.9 \%$ (physical neglect) to $12.7 \%$ (emotional abuse) among LGB youth - higher than rates found in comparable samples of heterosexual adolescents (Sterzing et al., 2016). Studies also demonstrate that different types of CAN tend to co-occur (Charak \& Koot, 2015; Higgins \& McCabe, 2000). Notably, these studies did not account for sexual orientation. Recently, in a study on 1,177 young people with expansive gender and sexual identities, Sterzing and colleagues (2017) found that $39.3 \%$ of the adolescents experienced polyvictimization (i.e., 10 or more adverse events) during the past year, nearly twice the prevalence found for youth drawn from the general population (Finkelhor, Ormrod, \& Turner, 2007). While this study did not explicitly assess the co-occurrence between maltreatment types, it is likely that many of the cases of polyvictimization involved multiple types of maltreatment, 
based on other studies on polyvictimization in high-risk youth or young adult populations (Charak et al., 2016; Charak, Ford, Modrowski, \& Kerig, 2018; Dierkhising, Ford, Branson, Grasso, \& Lee, 2018). Together, these studies suggest that the co-occurrence of types of childhood maltreatment is likely among LGB individuals.

\section{Face-to-face and Technology-mediated IPV}

Similar to CAN, higher rates of IPV have been found among people who identify as lesbian, gay, or bisexual compared to their heterosexual counterparts (Edwards, Sylaska, \& Neal, 2015; Messinger, 2011; Walters et al., 2013). In a nationally representative sample of adults from the United States, the lifetime prevalence of rape, physical violence and/or stalking by an intimate partner was $43.8 \%$ and $61.1 \%$ for lesbian and bisexual women, $26 \%$ and $37.3 \%$ for gay and bisexual men compared to $35 \%$ and $29 \%$ for heterosexual women and men, respectively (NISVS) (Walters et al., 2013). Further, a systematic review indicated a broader range - $1 \%$ to $97 \%$ - of prevalence rates of IPV among LGB individuals as a result of the use of different IPV definitions and assessment methods across studies (Edwards et al., 2015). However, the authors rightly state that this range says "...extremely little about the scope of the problem” (p. 113) (Edwards et al., 2015), and call for studies focusing on IPV among LGB individuals. Cybervictimization committed by an intimate partner (henceforth referred to as Cyber IPV) is distinct from face-to-face IPV in that the victim does not have the advantage of gauging a situation via physical and social cues that are available in an inperson interaction (Denegri-Knott \& Taylor, 2005; Watkins, Maldonado, \& DiLillo, 2016). Cyber IPV is also a multidimensional construct similar to face-to-face IPV, and comprises sexual and physical victimization, and cyberstalking behavior. Although not 
exclusively in LGB adults, a substantial body of research exists on cyber dating violence or IPV in adolescents, college students, and community samples of men and women (Watkins et al., 2016; Wright, 2014). For example, in an online sample of college students, $18.1 \%$ reported sexual cybervictimization, $29.2 \%$ and $45.1 \%$ reported psychological and stalking cyber IPV, respectively, during the last six months (Watkins et al., 2016). Thus, cyber IPV as a form of partner abuse with varying types and prevalence, is distinct from other forms of IPV, and hence an important area of research to be accounted for when examining IPV types even among LGB emerging adults.

\section{Associations between CAN and IPV}

Survivors of IPV often have been exposed to CAN, and studies have directed attention towards this association by examining lifetime victimization in interpersonal relationships_ childhood maltreatment and IPV—in LGB individuals (Anderson, Wandrey, Klossner, Cahill, \& Delahanty, 2017; Balsam et al., 2005). The trajectory between CAN and IPV is supported by the social learning theory (Bandura, 1977), which postulates that children learn how to behave in intimate partnerships through modeling relationships they are exposed to during their childhood. Witnessing and directly experiencing violence and victimization in the family increases the likelihood that an individual will perpetrate and/or be victimized in later romantic relationships (Ehrensaft et al., 2003); thus generating an association between CAN and IPV during adulthood. Additionally, in the transitional period from adolescence to emerging adulthood, victimization may lead to a trajectory of escalating psychosocial challenges. A longitudinal study assessing 16-20-year-old lesbian, gay, bisexual, transgender, and/or queer (LGBTQ) emerging adults at six time-points over a 3.5-year period found that 
victimization in adolescence was predictive of subsequent psychological distress in early adulthood (Birkett, Newcomb, \& Mustanski, 2015).

Like CAN, IPV is a heterogeneous phenomenon as individuals often report exposure to multiple types of IPV, such as psychological abuse, physical assault, and sexual assault. Using latent class analysis (LCA), a plethora of studies have established the heterogeneity in exposure to IPV victimization types in community samples (Carbone-López, Kruttschnitt, \& Macmillan, 2006; Hellmuth, Sullivan, \& Connell, 2015). By including childhood physical, sexual and emotional abuse along with IPV types in a LCA, four latent classes, namely, intimate partner violence dominant, child abuse and IPV, all forms, and all forms extreme were found among women (Davies et al., 2015). Further the latent class with exposure to more number of CAN and IPV types (i.e., the all form extreme class) was higher on depression and PTSD symptoms, and had poorer physical health (Davies et al., 2015). While no study to date has examined latent classes of CAN and IPV types in LGB individuals, it is an important area of research to provide adequate guidance for the development of prevention strategies and identification of at-risk individuals.

\section{Intersecting Identities Across Sexual Orientation and Race/Ethnicity}

Based on the minority stress hypothesis, a number intersections, including the one between LGB identity and race/ethnicity, heighten the risk for experiencing victimization and mental health challenges (Meyer, 2003). Studies indicate that bisexual women report higher rates of IPV than lesbian women (Goldberg \& Meyer, 2013; Messinger, 2011; Walters et al., 2013). In contrast, gay and bisexual men report greater rates of IPV than 
the general population; gay men also report higher IPV rates than bisexual men (Goldberg \& Meyer, 2013; Messinger, 2011).

Similarly in childhood maltreatment, bisexual adolescents were more likely to be exposed to any child maltreatment, and bisexuals and lesbians were more likely to be exposed to emotional abuse and physical neglect than their gay-identified counterparts (Sterzing et al., 2017). However, another study did not find any difference in childhood maltreatment types or in face-to-face IPV types between lesbian and gay individuals when compared with bisexual adults, although the latter were more likely to report a history of rape (non-intimate partner) than gay and lesbian individuals (Balsam et al., 2005). Findings are thus mixed, and hence another aim of the present study is to examine if LGB identities are differentially related to patterns of CAN and IPV in a community sample of emerging adults.

Studies examining people of color who identify as LGB and their exposure to victimization during childhood or in an intimate partner relationship are very limited; nonetheless the few existing studies suggest that, similar to their heterosexual counterparts, LGB people of color are at an increased risk of experiencing violence and victimization in interpersonal relationships (Balsam, Lehavot, Beadnell, \& Circo, 2010). For example, in a study on 172 racial and ethnically diverse LGBT adults, Black/African American individuals were more likely to report verbal or physical face-to-face IPV than Latino or White individuals (Reuter, Newcomb, Whitton, \& Mustanski, 2017). In another study on LGB individuals, Latinas/os had higher scores on childhood sexual abuse than Asian American and White individuals; Asian and African-Americans had higher scores on childhood physical abuse than White individuals (Balsam et al., 2010). Together these 
studies demonstrate that among LGB individuals, people of color are at a heightened risk of CAN and IPV compared to White individuals. The present study thus aims to examine the role of race and ethnicity in shaping LGB individuals' exposure to various patterns of CAN and IPV.

\section{Emotion Dysregulation and Mental Health Outcomes}

Studies suggest that survivors of early childhood victimization exhibit poorer emotion regulation skills than their non-maltreated counterparts (D'Andrea, Ford, Stolbach, Spinazzola, \& van der Kolk, 2012). The association between exposure to victimization and emotion dysregulation has also been found among LGB adults (Hatzenbuehler, Nolen-Hoeksema, \& Dovidio, 2009; Pachankis, Hatzenbuehler, Rendina, Safren, \& Parsons, 2015; Rogers et al., 2017). Emotion regulation is a transdiagnostic factor that shapes the development of internalizing and externalizing mental health challenges (Aldao, Gee, De Los Reyes, \& Seager, 2016). Given recent therapeutic advances designed to address emotion regulatory skills (Linehan, 1993), identifying obstacles to emotion regulation across patterns of victimization experienced by LGB individuals would help guide clinical interventions (Pachankis et al., 2015).

Regarding adverse health experiences related to marginalized identities, in a meta-analytic study, depression, anxiety, alcohol and drug use were found be to 1.5 times more common among LGB individuals versus their heterosexual counterparts (King et al., 2008). Based on the 2001-2002 National Epidemiologic Survey on Alcohol and Related Conditions (NESARC), it was found that bisexual and lesbian women were nearly twice as likely to report a lifetime mood mental health challenge, as were bisexual and gay men compared to heterosexual individuals (Bostwick, Boyd, Hughes, \& 
McCabe, 2010). Similarly, studies suggest that LGB people are more likely to excessively use alcohol and other substances than heterosexuals, often as a way to manage stressors tied to their marginalized identities (Burgard, Cochran, \& Mays, 2005; Meyer, 2003). The potential role of childhood maltreatment in these serious health challenges is highlighted by a recent studying showing LGB individuals' likelihood of attempted suicide being statistically mediated by a history of childhood sexual abuse for both men and women and childhood physical abuse for women (Flynn, Johnson, Bolton, \& Mojtabai, 2016).

\section{The Current Study}

First, the present study aimed to identify latent classes of victimization based on types of childhood abuse and neglect, namely, emotional, physical, and sexual abuse and emotional and physical neglect, adulthood face-to-face physical assault, sexual assault, psychological abuse, and injury, and three types of intimate partner psychological, sexual and stalking cybervictimization, among lesbian, gay, and bisexual (LGB) emerging adults. It was hypothesized that there would be varying patterns of exposure to childhood maltreatment, face-to-face IPV and cyber IPV types among LGB individuals, in that at least one latent class would have higher probabilities of exposure to CAN and IPV types (hypothesis 1) (Sterzing et al., 2017; Walters et al., 2013). Second, we examined the association between LGB status and racial/ethnicity, and latent class-membership, and based on the minority stress theory (Meyer, 2003), hypothesized that bisexual men and women (Goldberg \& Meyer, 2013; Messinger, 2011), and people of color, including White-Hispanics (Balsam et al., 2010; Reuter et al., 2017), would more likely be in classes with exposure to CAN and IPV (hypothesis 2). Third, it was hypothesized that 
latent classes with higher probabilities of exposure to childhood maltreatment and IPV would also be higher on emotion dysregulation, and symptoms of mental health challenges that include depression and anxiety symptoms, and alcohol use (hypothesis 3) (Bostwick et al., 2010).

\section{Methods}

\section{Participants}

The study sample included 288 emerging adults 18 to 29 years old $(M=25.35$, $S D=2.76)$, consisting of 165 women, 112 men, and 11 people self-identified as transgender or others (e.g., genderqueer, agender). The inclusion criteria in the present study were (i) between 18-29 years old, (ii) a United States citizen or legal resident, and (iii) have a current/former dating partner or spouse, and the exclusionary criterion was self-identifying as any sexual orientation (including heterosexual, pansexual, asexual) other than gay, lesbian, or bisexual.

On the basis of self-identifying sexual orientation, 71 identified as gay and their gender as men, 46 identified as lesbian and women, 119 identified as bisexual and women, 41 identified as bisexual and their gender identity as men, the remaining 11 identified their sexual orientation as gay, lesbian or bisexual, and their gender as agender, transgender, or genderqueer, and were labeled as 'gender diverse and expansive.' Participants' self-reported ethnic/racial backgrounds were as follows: $56.6 \%$ White NonHispanic, 26.0\% White Hispanic, 6.6\% Black or African-American, 5.2\% Asian, $4.2 \%$ Bi- or Multi-racial, and 1.4\% American Indian or Alaska Native. In terms of relationship status, $248(86.1 \%)$ were in an intimate relationship at the time of the study, with 58 (23.4\%) reporting being married, $51(20.5 \%)$ reported cohabitation, and $139(56.1 \%)$ 
reported just being in a relationship with an intimate partner. Forty participants $(13.9 \%)$ were not presently in an intimate relationship but had been in the past. The annual income of $10.4 \%$ of the participants was less then $\$ 15,000,15.6 \%$ had an income between $\$ 15,000-\$ 24,999,19.4 \%$ reported income in the range of $\$ 25,000$ to $\$ 34,999,21.2 \%$ had an income between $\$ 35,000-\$ 49,000,19.8 \%$ were in the range of $\$ 50,000-\$ 74,999$, and $13.5 \%$ had an annual income of $\$ 75,000$ or more.

\section{Procedure}

Participants were recruited online via Amazon's Mechanical Turk (Amazon MTurk), a sourcing platform considered a viable research participatory tool for gathering high-quality data from a diverse population (Buhrmester, Kwang, \& Gosling, 2011). Studies indicate that data from Amazon MTurk outperforms panel data collected by professional marketing research companies, and is comparable to data from college students (Kees, Berry, Burton, \& Sheehan, 2017). Through MTurk, a pool of participants or "Workers," complete Human Intelligence Tasks (HITs) such as research surveys for compensation. For the present study, there was no mention that participants must selfidentify as lesbian, gay, or bisexual in the consent form. If they consented, participants were taken directly to the survey and asked few screener demographic questions, including sexual orientation (heterosexual, gay, lesbian, bisexual, other, e.g., asexual, pansexual, queer). If participants chose "heterosexual" or "other," the survey was not administered. They were taken to the end of the survey, thanked for their time and cooperation, and informed that they were not eligible for the study and would not be paid. Eligible participants who completed the survey were compensated with $\$ 3.00$ for their participation. Ten attention check items were distributed through the survey of which 
$80 \%$ had to be answered correctly for data to be analyzed. Data collection took place during July-August 2017. The Institutional Review Board (IRB) at the [MASKED FOR REVIEW] approved the study procedures.

\section{Measures}

Childhood Maltreatment. The short form of the Childhood Trauma Questionnaire (CTQ-SF, Bernstein et al., 2003) was used to evaluate childhood maltreatment histories across five different domains: emotional abuse, physical abuse, sexual abuse, emotional neglect, and physical neglect. The CTQ-SF is a 5-point Likerttype scale $(1=$ never true $; 5=$ very often true $)$ with five items each, representing five types of abuse/neglect. The 25-item brief version of the CTQ demonstrates high criterionbased validity and is viable across diverse clinical and community samples (Bernstein et al., 2003; Charak \& Koot, 2014). In the present study, the Cronbach's alpha $(\alpha)$ for each of the five subscales showed high (Emotional Abuse $\alpha=.90$, Physical Abuse $\alpha=.86$, Sexual Abuse $\alpha=.94$, Emotional Neglect $\alpha=.88$ ) or acceptable (Physical Neglect $\alpha=$ .71) levels of internal consistency.

Face-to-face intimate partner victimization. A referent time of one year was used to evaluate intimate partner victimization enacted in-person during a current or former intimate relationship via the short form of the Revised Conflict Tactics Scale (Straus \& Douglas, 2004). The scale measures three tactics employed when conflict arises in intimate relationships, negotiation, physical assault, and psychological aggression, as well as the two supplemental scales, injury from assault and sexual coercion. In the present study, we used the scales of physical assault, psychological aggression, sexual coercion, and injury. Specific to LGB identity, two items were added 
under psychological aggression in face-to-face situations ('My partner threatened to out me...' and 'My partner asks or tells me to act straight around certain people') as recommended by a previous study (Balsam et al., 2005). Frequency of abuse of both the victim was rated on a 7-point Likert-scale, ranging from 1 (once in the past year) to 8 (this has never happened), with the additional option of indicating 7 (not in the past year, but it did happen before). A dichotomous variable $(0=$ absent $; 1=$ present $)$ was created to indicate lifetime IPV victimization status for each subscale; if any item corresponding to each subscale was endorsed, lifetime victimization was considered present.

Cybervictimization among intimate partners. Adult cyber IPV was measured via the Cyberaggression in Relationships Scale (CARS) (Watkins et al., 2018). The CARS assesses an individual's experiences on three factors: psychological aggression, sexual victimization, and stalking behaviors. Studies examining CARS construct validity suggest that it is positively related to trait anger, relationship jealousy, alcohol use, mental health challenges, and is negatively related to relationship satisfaction (Watkins et al., 2018). Again, specific to LGB identity, two items were added to psychological aggression occurring via cyberspace ('My partner threatened to out me...' and 'My partner asks or tells me to act straight around certain people') as recommended by a previous study (Balsam et al., 2005). Items were rated on an 7-point Likert-type scale (0 $=$ this has never happened; $6=$ (more than 20 times in the past year), with the additional option to indicate option 7 (not in the past year, but it did happen before). A dichotomous variable $(0=$ absent $; 1=$ present $)$ was created to indicate lifetime victimization status for each factor. The endorsement of any item corresponding to each subscale indicated lifetime victimization status. 
Emotion dysregulation. The 16-item version of the Difficulties in Emotion Regulation Scale (DERS-16) (Bjureberg et al., 2016) is a self-report measure of an individual's typical levels of emotion dysregulation across five areas: nonacceptance of emotional responses, difficulties engaging in goal directed behaviors when distressed, difficulties controlling impulsive behaviors when distressed, limited access to effective strategies for emotion regulation, and lack of emotional clarity. The DERS-16 has retained excellent internal consistency when compared with the original 36-item scale (Gratz \& Roemer, 2004; Fowler et al., 2014) and has been shown to be psychometrically sound in clinical and community samples (Bjureberg et al., 2016; Miguel, Giromini, Colombarolli, Zuanazzi, \& Zennaro, 2017). Emotion regulation challenges were rated on a 5-point Likert-scale, ranging from 1 (almost never) to 5 (almost always) and responses were summed. In the present study, the Cronbach's alpha for each of the five subscales in the DERS-16 was acceptable $(\alpha s=.88$ to .92$)$.

Symptoms of depression. The Patient Health Questionnaire (PHQ) (Kroenke, Spitzer, \& Williams, 2001) is a 9-item self-report measure that assesses each of the nine DSM-IV criteria for depression (e.g., little interest or pleasure in doing things). Depressive symptoms experienced over the past month were rated on a 4-point Likerttype scale $(0=$ not at all; $3=$ nearly every day $)$ and responses were summed. Increase in PHQ-9 depression severity scores is associated with deteriorating functionality in primary care patients, thus demonstrating adequate construct validity (Kroenke et al., 2001). Cronbach's alpha for the PHQ was .94 in the present study.

Symptoms of anxiety. Anxiety symptoms were measured using the Generalized Anxiety Disorder (GAD)-7 scale (Spitzer, Kroenke, Williams, \& Löwe, 2006). Anxiety 
symptoms (e.g., being restless, worrying too much about different things) experienced in the past two weeks were rated on a 4-point Likert-scale ranging from 0 (not at all sure) to 3 (nearly every day) and responses were summed. In the general population, GAD-7 has demonstrated good internal consistency, and is negatively associated with self-esteem (Lowe et al., 2008). In the present study, the Cronbach's alpha for the GAD-7 was .94.

Alcohol use. Alcohol-related challenges were measured via the Alcohol Use Disorders Identification Test (AUDIT) (Saunders, Aasland, Babor, de la Fuente, \& Grant, 1993), which assesses drinking behavior, adverse reactions, and challenges experienced in the past six months. Alcohol behaviors were rated on a 5-point Likert-type scale $(0=$ never; 4 = daily or almost daily) and summed. The AUDIT demonstrates high sensitivity and specificity, typically higher than other self-report screening measures, and has good test-retest and internal consistency (Reinert \& Allen, 2002). In the current study, the Cronbach's alpha of the AUDIT was .80.

\section{Statistical Analyses}

Descriptive statistics were conducted in IBM SPSS v. 25. First, a latent class analysis (LCA) was performed to determine the number of heterogeneous groups with homogeneity within each group based on exposure to 12 different types of childhood abuse and neglect and adulthood victimization, both in-person and technology-mediated. LCA estimates the posterior probabilities of class membership or size of the class (Nylund, Asparouhov, \& Muthén, 2007). Better fitting models are reflected by significant $p$ values for the Lo-Mendell-Rubins likelihood ratio test (LMR), and the Bootstrap likelihood ratio test (BLRT), lower values on the Akaike Information Criteria (AIC), the Bayesian Information Criteria (BIC), and the sample size adjusted BIC (Adjusted BIC), 
and higher entropy values indicate clearer classification (Nylund et al., 2007). Further, model fit and the resultant class solution should be judged based on substantive meaningfulness of the classes, i.e., the classes should be distinct and meaningful (Nylund et al., 2007). The LCA analysis was conducted using Mplus 8.0 software employing maximum likelihood estimation with robust standard errors (MLR).

After obtaining the latent classes, multinomial logistic regression was performed to assess predictors of class-membership using the 3-step approach through the AUXILIARY command in Mplus (Asparouhov \& Muthén, 2014). This approach takes into account the inaccuracy of class assignment when assessing latent class predictors in multinomial regressions. Predictors included sexual orientation (gay men vs. bisexual men; lesbian women vs. bisexual women; bisexual men vs. bisexual women) and race/ethnicity (White non-Hispanic vs. people of color groups, including Hispanic individuals). Next, to compare emotion dysregulation, depressive symptoms, anxiety symptoms, and alcohol use between latent classes, outcome variables were treated as having unequal means and variances, and were compared using the 3-step approach while taking into account the inaccuracy of class assignment.

\section{Results}

All participants had at least $80 \%$ of responses correct on the attention check items. Distributions of ethnoracial status (i.e., people of color), and CAN and IPV types across sexual and gender identities are presented in Table 1.

\section{Latent Classes of Childhood Maltreatment and IPV}

No missing data were present in the current study as the option of forced response was used. A series of LCA models with two to six class solutions were estimated. A five- 
class solution was found to be optimal based on several goodness-of-fit indices (see Table 2), and meaningfulness of the classes. One likelihood ratio test (i.e., LMR), and the information criterion of BIC, favored the five-class solution. Although the sample size adjusted-BIC favored a six-class solution, simulation studies suggest that BIC is a robust indicator of the number of latent classes extracted (Nylund et al., 2007). Thus, in the present study a five-class solution was selected. Additionally, entropy was high (i.e., .89) and the average posterior probability for most likely latent class membership ranged from .90 to .99 for the five-class solution, which suggests good class determination.

The item probabilities across the five latent-classes are presented in Table 3. Based on the endorsement of CAN and IPV (both face-to-face and technology-mediated) items, the five latent classes were labeled. Class $1(n=55 ; 28.2 \%$ gay; $15.2 \%$ lesbian; $32.7 \%$ bisexual women; $19.5 \%$ bisexual men; $26.4 \%$ people of color) was labeled 'high victimization' as it had the highest probabilities of exposure to all types of CAN and sexual cyber IPV by a partner. Class $2(n=73 ; 11.3 \%$ gay; $15.2 \%$ lesbian; $38.7 \%$ bisexual women; $9.8 \%$ bisexual men; $20.8 \%$ people of color) was labeled "childhood emotional abuse and neglect' as it had high probabilities of childhood abuse and neglect but these were lower than Class 1. This class also had low to moderate levels of probabilities of cyber IPV (i.e., .068 to .307$)$. Class $3(n=53 ; 18.3 \%$ gay; $19.6 \%$ lesbian; 19.3\% bisexual women; $19.5 \%$ bisexual men; $17.6 \%$ people of color) had the highest probability of technology-mediated intimate partner psychological and stalking, and was labeled as 'cybervictimization'. Notably, this class had a lower probability of sexual cyber IPV than Class 1 but higher than the other classes. Class $4(n=34 ; 16.9 \%$ gay; 15.2\% lesbian; $7.6 \%$ bisexual women; $14.6 \%$ bisexual men; $13.6 \%$ people of color) had 
the highest probabilities of face-to-face IPV and was termed 'adult face-to-face IPV.'

This class also had some probabilities of exposure to CAN and cyber IPV types (i.e., .175

to .562 ). Class 5 ( $n=73 ; 25.4 \%$ gay; $34.8 \%$ lesbian; $19.3 \%$ bisexual women; $36.6 \%$

bisexual men; $21.6 \%$ people of color) had the lowest probabilities of all types of CAN, and psychological and stalking cyber IPV, and was termed as 'lower victimization.' Even in the lower victimization class the probability of victimization ranged up to 0.408 . Thus, all latent classes had some probability of most types victimization across childhood and in intimate partner relationships.

\section{Demographic and Clinical Outcomes Across the Latent Classes}

Multinomial logistic regressions results suggested that participant's gender-and bisexual identity (versus gay/lesbian sexual identity), and people of color (including Hispanics) status did not differentiate the IPV classes (Class 3 and 4) from the lower victimization class (Class 5) (see Table 4). Individual's gender-and bisexual identities also did not differentiate the high (Class 1) versus lower (Class 5) victimization classes, but White Non-Hispanic people were less likely than people of color to be in the high victimization class compared to the low victimization class. Participant's gender-and bisexual identities did differentiate the members of the child emotional abuse and neglect class from members of the lower victimization class, with bisexual men and bisexual women, as compared to gay men and lesbian women, more likely to be in the childhood emotional abuse and neglect class versus the lower victimization class, respectively; and bisexual women, as compared to bisexual men, also more likely to be in the childhood emotional abuse and neglect class versus the lower victimization class. 
Table 5 indicates the LCA results for class membership and indicators of emotion dysregulation, depressive symptoms, anxiety symptoms, and alcohol use. Class membership was significantly related to all the outcome variables as evidenced by the significant chi-square tests in Table 5. Specifically, members of the high victimization and childhood emotional abuse and neglect classes reported higher levels of emotion dysregulation, symptoms of depression, and anxiety symptoms as compared to the other classes of victimization. Members of the high victimization class also reported higher levels of alcohol use when compared with the childhood emotional abuse and neglect, adult face-to-face IPV, and lower victimization classes. Participants in the cybervictimization IPV class also reported higher levels of all mental/behavioral health challenges than the face-to-face IPV or lower victimization classes.

\section{Discussion}

The primary purpose of this study was to examine the different patterns of childhood maltreatment types and intimate partner victimization (face-to-face and technology-mediated) in a community sample of individuals who identify as lesbian, gay, and bisexual. Further, the study investigated differences across people who identify as LGB and people of color (predictor variables), and distal outcomes, including emotion dysregulation, depressive symptoms, anxiety, and alcohol use across the latent classes. Consistent with hypothesis 1 , findings suggested a five class-solution including distinct sub-groups whose members reported either exposure to multiple forms of childhood maltreatment and adult cybervictimization (i.e., the high victimization class), childhood emotional abuse and neglect, face-to-face intimate partner victimization during adulthood, cybervictimization in adulthood, or lower lifetime victimization. Hypothesis 2 
was partially supported in that people of color (including White Hispanics) were more likely to be in high victimization class, and bisexual individuals were more likely to be in the childhood emotional abuse and neglect class than the lower victimization class. Also, bisexual women were more likely to be in the childhood emotional abuse and neglect class compared to bisexual men. In partial support of hypothesis 3, the class with higher probabilities of CAN and IPV, that is the high victimization class, was higher than three other classes, namely, cybervictimization, adult face-to-face IPV, and lower victimization on emotion dysregulation, symptoms of depression and anxiety, and alcohol use.

Notably, high victimization class was greater than childhood emotional abuse and neglect class only on alcohol use.

Akin to prior studies on community-based samples (Davies et al., 2015), present findings showed heterogeneity in childhood maltreatment and IPV experiences among LGB emerging adults. While previous research on LGB individuals has documented the presence of CAN and adult victimization separately, none have simultaneously examined patterns of victimization during childhood and adulthood (Balsam et al., 2005). With the inclusion of cyber IPV, the present study found classes varying across experiences of interpersonal revictimization (i.e., high victimization class), childhood abuse and neglect (i.e., the childhood emotional abuse and neglect class), intimate partner violence victimization (i.e., cybervictimization and adult face-to-face IPV), and a class with lower victimization. Latent classes differed primarily in the probabilities of victimization type, and were labeled based on the predominant victimization types endorsed. No latent class emerged, however, with exposure to only childhood maltreatment or only to IPV, 
supporting the social learning theory that suggests an association between CAN and adult IPV (Manchikanti Gomez, 2011).

Findings also suggest a class—cybervictimization—with a probability of all members $(n=53 ; 18.4 \%$ of the total sample) endorsing technology-mediated psychological victimization and cyber stalking. Our findings add to the existing literature by emphasizing the presence of cyber IPV among LGB emerging adults. Notably, it was Class 1 that had the highest probability of sexual cyber IPV. Similarly, the IPV class indicated all members being exposed to various types of face-to-face IPV $(n=34 ; 11.8 \%$ of the total sample). Together, these findings inform the extant literature in that LGB individuals are at-risk of interpersonal victimization with varying patterns of IPV, including technology-mediated IPV, and prior exposure to childhood maltreatment types. The present findings can help support LGB emerging adults and facilitate in the formulation of prevention strategies, in light of studies demonstrating that many LGB victims experience barriers to social support systems, increased challenges with disclosure and help-seeking, and fewer available services tailored to their needs (Edwards et al., 2015).

The finding that participants who endorsed in-person IPV did not tend to endorse childhood maltreatment was unexpected in light of prior evidence of a relationship between childhood maltreatment and IPV (Renner \& Whitney, 2012). However, a longitudinal study that followed preschool children into adulthood found that adolescent dating violence victimization and peer approval of dating violence were predictive of adult IPV, while child maltreatment was predictive of IPV perpetration (Herrenkohl \& Jung, 2016). An independent three-decade prospective study beginning in early childhood 
similarly found that childhood maltreatment was predictive of adult IPV (and child abuse and criminal violence) perpetration (Milaniak \& Widom, 2015). Further research is needed to determine whether sexual and physical IPV victimization occurs independently of childhood maltreatment among LGBTQ emerging adults, and whether childhood maltreatment is significantly associated with IPV perpetration in this population.

In support of the minority stress theory (Meyer, 2003), findings indicated that people of color (including White Hispanics) were more likely to be in the high victimization class than the lower victimization class. Thus, people of color may be at heightened risk for victimization among LGB individuals (Balsam et al., 2005), which also corresponds with IPV victimization among heterosexual people of color. Further, bisexual individuals were more likely to be in the childhood emotional abuse and neglect class (versus the lower victimization class), suggestive of exposure to childhood maltreatment. Further, bisexual women were more likely to be in the childhood emotional abuse and neglect class than bisexual men. Notably, we did not find any differences across LGB identities between the high victimization class, other classes with predominant IPV exposure (i.e., cybervictimization and adult face-to-face IPV), and the lower victimization class as found in prior studies on IPV (Goldberg \& Meyer, 2013; Messinger, 2011). Nonetheless, our findings corroborate prior literature that bisexual women and men report higher childhood maltreatment (Sterzing et al., 2017, 2016) when compared to lesbian women or gay men, respectively. The present findings suggest that clinicians working with LGB people of color, and bisexual individuals, particularly bisexual women, with experiences of victimization during childhood should be sensitive to the nuanced challenges faced by their clients. 
Further the cumulative effect of exposure to CAN and IPV was found across emotion dysregulation, symptoms of anxiety and depression, and alcohol use in that latent classes with higher probabilities of exposure to more types of CAN and IPV—-high victimization, childhood emotional abuse and neglect, cybervictimization, adult face-toface IPV—reported greater scores than the lower victimization class. These findings are in line with studies on community samples supporting the cumulative risk hypothesis of CAN and IPV types, and their compounding and detrimental effect on the mental and physical health of an individual (Davies et al., 2015; Herrenkohl \& Jung, 2016). Notably, high victimization and childhood emotional abuse and neglect classes had the highest probabilities of LGB emerging adults endorsing exposure to multiple forms of childhood abuse and neglect when compared to the other classes. Findings contribute to present understandings surrounding mental and physical health challenges among LGB young adults, suggesting that those with both childhood maltreatment and IPV exposure, and those with predominantly multiple types of childhood maltreatment are at a higher risk of experiencing emotion dysregulation, symptoms of depression and anxiety (Balsam et al., 2005; McLaughlin, Hatzenbuehler, Xuan, \& Conron, 2012), and alcohol use (Talley et al., 2016). Although not an aim of the present study, findings indicated that those with cybervictimization in the form of stalking and psychological abuse (i.e., the cybervictimization class) were at higher risk of emotion dysregulation and mental health challenges compared to those with face-to-face victimization. In sum, it is important to examine universal risk factors, such as patterns of childhood maltreatment and IPV types, including cybervictimization, among LGB populations to provide effective tailor-made services and interventions (e.g., LGB affirmative CBT) (Pachankis et al., 2015). 


\section{Limitations}

This study's findings should be considered within the context of the following limitations. First, the present study involved a convenience sample of self-selected participants who may not be representative of LGB emerging adults generally, and relied on participants' memory and willingness to report experiences of CAN and IPV and related outcomes in an online study (i.e., using Amazon MTurk) that limits the generalizability to other samples (Walters, Christakis, \& Wright, 2018). However, the use of online data collection forums may paradoxically increase the likelihood of reporting sensitive information in the absence of an interviewer (Tourangeau \& Smith, 1996). Second, self-report questionnaires were used in the present study, which can create a recall bias especially of retrospective reports pertaining to childhood maltreatment. Notably, prior studies suggest that when behaviorally specific questions are used to assess victimization (as done in the present study), the accuracy of reporting may increase (Fricker, Smith, Davis, \& Hanson, 2003). Third, the effect of person of color status excluding White-Hispanics (e.g., Black/African-American, Asian-American; $n=50$ ) on lifetime victimization, and the role of LGB-gender diverse and expansive identities $(n=$ 11) on class-membership could not be examined due to the sample size being small. Additionally, the adult face-to-face IPV class was relatively small $(n=34)$. Further studies should oversample for both race and ethnicity to examine their differential association with interpersonal victimization - face-to-face and via cyberspace - among LGB individuals. Fourth, the current findings are based on a cross-sectional design and, thus, preclude conclusions as to the precise nature and direction of the relation between patterns of CAN and IPV, and emotion dysregulation and alcohol use. Indeed, it is likely 
that this relation is bidirectional in nature, with victimization resulting in greater emotion dysregulation and alcohol use, and emotion dysregulation or alcohol use increasing the risk for future revictimization (Bryan et al., 2016).

\section{Implications for practice and research}

Nonetheless, the present findings are consistent with earlier empirical research and theory, and thus have important implications for intervention and future research with individuals who identify as LGB. Clinicians should be cognizant that LGB individuals can experience multiple universal risk factors, such as childhood maltreatment and IPV, and service providers should conduct a thorough assessment of victimization history. Childhood maltreatment, in-person physical and sexual IPV victimization, and IPV cybervictimization each should be assessed, as study findings indicate that they can occur independently as well as in combination. When IPV takes the form of cybervictimization, assessment should rule in/out childhood maltreatment as an additional contributor to psychosocial challenges. The role of adolescent dating IPV and peer approval of dating violence also should be considered when in-person IPV is identified, given prior evidence that these adolescent experiences rather than childhood maltreatment may signal risk for adult IPV victimization (Herrenkohl \& Jung, 2016).

While all forms of abuse, neglect, and assault can be potentially harmful, recognizing the heterogeneity in victimization experiences (in both childhood and adulthood) among people who are LGB may fruitfully inform clinical interventions, as different types of victimization may be distinctively associated with negative outcomes. For example, in the present study those with exposure to both childhood abuse/neglect (including those with revictimization experiences) and IPV reported greater difficulties 
with emotion regulation, mental health challenges, and risky behavior (i.e., alcohol use) than those with fewer victimization experiences. Interventions directed towards generating awareness among clinicians and society at large about the various minority stressors faced by LGB survivors of CAN and IPV, especially LGB people of color and bisexual individuals in general, would reduce stigmatization and in turn encourage survivors to seek out beneficial services. Moreover, early interventions to help prevent (re)victimization in adulthood, and tailored clinical interventions directed towards the management of emotion regulatory skills and substance use, would likely benefit LGB survivors in significant ways. 


\section{References}

Aldao, A., Gee, D. G., De Los Reyes, A., \& Seager, I. (2016). Emotion regulation as a transdiagnostic factor in the development of internalizing and externalizing psychopathology: Current and future directions. Development and Psychopathology. https://doi.org/10.1017/S0954579416000638

Anderson, R. E., Wandrey, R. L., Klossner, S. C., Cahill, S. P., \& Delahanty, D. L. (2017). Sexual minority status and interpersonal victimization in college men. Psychology of Sexual Orientation and Gender Diversity, 4(1), 130-136. https://doi.org/10.1037/sgd0000204

Arnett, J. J. (2000). Emerging adulthood: A theory of development from the late teens through the twenties. American Psychologist. https://doi.org/10.1037/0003066X.55.5.469

Asparouhov, T., \& Muthén, B. (2014). Auxiliary Variables in Mixture Modeling: ThreeStep Approaches Using Mplus. Structural Equation Modeling. https://doi.org/10.1080/10705511.2014.915181

Balsam, K. F., Lehavot, K., Beadnell, B., \& Circo, E. (2010). Childhood abuse and mental health indicators among ethnically diverse lesbian, gay, and bisexual adults. Journal of Consulting and Clinical Psychology, 78(4), 459-468. https://doi.org/10.1037/a0018661

Balsam, K. F., Rothblum, E. D., \& Beauchaine, T. P. (2005). Victimization over the life span: A comparison of lesbian, gay, bisexual, and heterosexual siblings. Journal of Consulting and Clinical Psychology, 73(3), 477-487. https://doi.org/10.1037/0022006X.73.3.477

Bandura, A. (1977). Social learning theory. In Social Learning Theory. https://doi.org/10.1111/j.1460-2466.1978.tb01621.x

Bernstein, D. P., Stein, J. A., Newcomb, M. D., Walker, E., Pogge, D., Ahluvalia, T., ... Zule, W. (2003). Development and validation of a brief screening version of the Childhood Trauma Questionnaire. Child Abuse \& Neglect. https://doi.org/10.1016/S0145-2134(02)00541-0

Birkett, M., Newcomb, M. E., \& Mustanski, B. (2015). Does it get better? a longitudinal analysis of psychological distress and victimization in lesbian, gay, bisexual, transgender, and questioning youth. Journal of Adolescent Health, 56(3), 280-285. https://doi.org/10.1016/j.jadohealth.2014.10.275

Bjureberg, J., Ljótsson, B., Tull, M. T., Hedman, E., Sahlin, H., Lundh, L. G., ... Gratz, K. L. (2016). Development and Validation of a Brief Version of the Difficulties in Emotion Regulation Scale: The DERS-16. Journal of Psychopathology and Behavioral Assessment. https://doi.org/10.1007/s10862-015-9514-X

Black, M.C.; Basile, K.C.; Smith, S.G.; Walters, M.L.; Merrick, M.T.; Chen, J.; Stevens, M. R. (2010). National Intimate Partner and Sexual Violence Survey 2010 Summary Report. National Center for Injury Prevention and Control, Centers for Disease Control and Prevention, 1-124. https://doi.org/10.1093/oxfordhb/9780199844654.013.0003

Bostwick, W. B., Boyd, C. J., Hughes, T. L., \& McCabe, S. E. (2010). Dimensions of sexual orientation and the prevalence of mood and anxiety disorders in the United States. American Journal of Public Health, 100(3), 468-475. 
https://doi.org/10.2105/AJPH.2008.152942

Bryan, A. E. B., Norris, J., Abdallah, D. A., Stappenbeck, C. A., Morrison, D. M., Davis, K. C., ... Zawacki, T. (2016). Longitudinal Change in Women's Sexual Victimization Experiences as a Function of Alcohol Consumption and Sexual Victimization History: A Latent Transition Analysis. Psychology of Violence. https://doi.org/10.1037/a0039411

Buhrmester, M., Kwang, T., \& Gosling, S. D. (2011). Amazon's Mechanical Turk: A new source of inexpensive, yet high quality, data? Perspectives on Psychological Science. https://doi.org/10.1177/1745691610393980

Burgard, S. A., Cochran, S. D., \& Mays, V. M. (2005). Alcohol and tobacco use patterns among heterosexually and homosexually experienced California women. Drug and Alcohol Dependence. https://doi.org/10.1016/j.drugalcdep.2004.07.007

Carbone-López, K., Kruttschnitt, C., \& Macmillan, R. (2006). Patterns of intimate partner violence and their associations with physical health, psychological distress, and substance use. Public Health Reports (Washington, D.C. : 1974). https://doi.org/10.1177/003335490612100406

Charak, R., Byllesby, B. M., Roley, M. E., Claycomb, M. A., Durham, T. A., Ross, J., ... Elhai, J. D. (2016). Latent classes of childhood poly-victimization and associations with suicidal behavior among adult trauma victims: Moderating role of anger. Child Abuse and Neglect, 62, 19-28. https://doi.org/10.1016/j.chiabu.2016.10.010

Charak, R., Ford, J. D., Modrowski, C. A., \& Kerig, P. K. (2018). Polyvictimization, Emotion Dysregulation, Symptoms of Posttraumatic Stress Disorder, and Behavioral Health Problems among Justice-Involved Youth: a Latent Class Analysis. Journal of Abnormal Child Psychology. https://doi.org/10.1007/s10802-018-0431-9

Charak, R., \& Koot, H. M. (2014). Abuse and neglect in adolescents of Jammu, india: The role of gender, family structure, and parental education. Journal of Anxiety Disorders, 28(6), 590-598. https://doi.org/10.1016/j.janxdis.2014.06.006

Charak, R., \& Koot, H. M. (2015). Severity of maltreatment and personality pathology in adolescents of Jammu, India: A latent class approach. Child Abuse and Neglect, 50, 56-66. https://doi.org/10.1016/j.chiabu.2015.05.010

D’Andrea, W., Ford, J., Stolbach, B., Spinazzola, J., \& van der Kolk, B. A. (2012). Understanding Interpersonal Trauma in Children: Why We Need a Developmentally Appropriate Trauma Diagnosis. American Journal of Orthopsychiatry. https://doi.org/10.1111/j.1939-0025.2012.01154.X

Davies, L., Ford-Gilboe, M., Willson, A., Varcoe, C., Wuest, J., Campbell, J., \& ScottStorey, K. (2015). Patterns of Cumulative Abuse Among Female Survivors of Intimate Partner Violence: Links to Women's Health and Socioeconomic Status. Violence Against Women, 21(1), 30-48. https://doi.org/10.1177/1077801214564076

Denegri-Knott, J., \& Taylor, J. (2005). The labeling game: A conceptual exploration of deviance on the internet. Social Science Computer Review. https://doi.org/10.1177/0894439304271541

Dierkhising, C. B., Ford, J. D., Branson, C., Grasso, D. J., \& Lee, R. (2018). Developmental timing of polyvictimization: Continuity, change, and association with adverse outcomes in adolescence. Child Abuse and Neglect, (May 2017), 0-1. https://doi.org/10.1016/j.chiabu.2018.07.022

Edwards, K. M., Sylaska, K. M., \& Neal, A. M. (2015). Intimate partner violence among 
sexual minority populations: A critical review of the literature and agenda for future research. Psychology of Violence, 5(2), 112-121. https://doi.org/10.1037/a0038656

Ehrensaft, M. K., Cohen, P., Brown, J., Smailes, E., Chen, H., \& Johnson, J. G. (2003). Intergenerational transmission of partner violence: A 20-year prospective study. Journal of Consulting and Clinical Psychology. https://doi.org/10.1037/0022006X.71.4.741

Finkelhor, D., Ormrod, R. K., \& Turner, H. A. (2007). Poly-victimization: A neglected component in child victimization. Child Abuse and Neglect. https://doi.org/10.1016/j.chiabu.2006.06.008

Flynn, A. B., Johnson, R. M., Bolton, S. L., \& Mojtabai, R. (2016). Victimization of Lesbian, Gay, and Bisexual People in Childhood: Associations with Attempted Suicide. Suicide \& Life-Threatening Behavior. https://doi.org/10.1111/sltb.12228

Fowler, C. J., Charak, R., Elhai, J. D., Allen, J. G., Frueh, C. B., \& Oldham, J. M. (2014). Construct validity and factor structure of the difficulties in emotion regulation scale among adults with severe mental illness. Journal of Psychiatric Research, 58, 175180.

Fricker, A. E., Smith, D. W., Davis, J. L., \& Hanson, R. F. (2003). Effects of context and question type on endorsement of childhood sexual abuse. Journal of Traumatic Stress. https://doi.org/10.1023/A:1023748124626

Goldberg, N. G., \& Meyer, I. H. (2013). Sexual Orientation Disparities in History of Intimate Partner Violence: Results From the California Health Interview Survey. Journal of Interpersonal Violence, 28(5), 1109-1118. https://doi.org/10.1177/0886260512459384

Gratz, K. L., Roemer, L. (2004). Multidimensional assessment of emotion regulation and dysregulation: development, factor structure, and initial validation of the difficulties in emotion regulation scale. Journal of Psychopathology and Behavioral Assessment, 26, 41-54.

Hatzenbuehler, M. L., Nolen-Hoeksema, S., \& Dovidio, J. (2009). How Does Stigma "'Get Under the Skin",? The Mediating Role of Emotion Regulation.

Hellmuth, J. C. H., Sullivan, T. P., \& Connell, C. M. (2015). Profiles of Intimate Partner Violence Victimization, Substance Misuse, and Depression Among Female Caregivers Involved with Child Protective Services. Journal of Family Violence, 30(8), 999-1005. https://doi.org/10.1007/s10896-015-9690-1

Herrenkohl, T. I., \& Jung, H. (2016). Effects of child abuse, adolescent violence, peer approval and pro-violence attitudes on intimate partner violence in adulthood. Criminal Behaviour and Mental Health, 26(4), 304-314. https://doi.org/10.1002/cbm.2014

Higgins, D. J., \& McCabe, M. P. (2000). Multi-type maltreatment and the long-term adjustment of adults. Child Abuse Review, 9, 6-18.

Kees, J., Berry, C., Burton, S., \& Sheehan, K. (2017). An analysis of data quality: professional panels, student subject pools, and amazon's mechanical turk. Journal of Advertising, 46, 141-155.

King, M., Semlyen, J., Tai, S. S., Killaspy, H., Osborn, D., Popelyuk, D., \& Nazareth, I. (2008). A systematic review of mental disorder, suicide, and deliberate self harm in lesbian, gay and bisexual people. BMC Psychiatry. https://doi.org/10.1186/1471244X-8-70 
Kroenke, K., Spitzer, R. L., \& Williams, J. B. W. (2001). The PHQ-9. Journal of General Internal Medicine. https://doi.org/10.1046/j.1525-1497.2001.016009606.x

Linehan, M. M. (1993). Cognitive-behavioral treatment of borderline personality disorder. Cognitive-behavioral treatment of borderline personality disorder. https://doi.org/10.1017/CBO9781107415324.004

Lowe, B., Decker, O., Muller, S., Brahler, E., Schellberg, D., Herzog, W., Herzberg, P. Y. (2008). Validation and standardization of the generalized anxiety disorder screener (GAD-7) in the general population. Medical Care, 46, 266-274.

Manchikanti Gomez, A. (2011). Testing the Cycle of Violence Hypothesis: Child Abuse and Adolescent Dating Violence as Predictors of Intimate Partner Violence in Young Adulthood. Youth \& Society. https://doi.org/10.1177/0044118X09358313

McLaughlin, K. A., Hatzenbuehler, M. L., Xuan, Z., \& Conron, K. J. (2012). Disproportionate exposure to early-life adversity and sexual orientation disparities in psychiatric morbidity. Child Abuse and Neglect, 36(9), 645-655. https://doi.org/10.1016/j.chiabu.2012.07.004

Messinger, A. M. (2011). Invisible Victims: Same-Sex TPV in the National Violence Against Women Survey. Journal of Interpersonal Violence, 26(11), 2228-2243. https://doi.org/10.1177/0886260510383023

Meyer, I. H. (2003). Prejudice, social stress, and mental health in lesbian, gay, and bisexual populations: Conceptual issues and research evidence. Psychological Bulletin. https://doi.org/10.1037/0033-2909.129.5.674

Miguel, F. K., Giromini, L., Colombarolli, M. S., Zuanazzi, A. C., \& Zennaro, A. (2017). A Brazilian Investigation of the 36- and 16-Item Difficulties in Emotion Regulation Scales. Journal of Clinical Psychology. https://doi.org/10.1002/jclp.22404

Milaniak, I., \& Widom, C. S. (2015). Does child abuse and neglect increase risk for perpetration of violence inside and outside the home? Psychology of Violence. https://doi.org/10.1037/a0037956

Nylund, K. L., Asparouhov, T., \& Muthén, B. O. (2007). Deciding on the number of classes in latent class analysis and growth mixture modeling: A Monte Carlo simulation study. Structural Equation Modeling. https://doi.org/10.1080/10705510701575396

Pachankis, J. E., Hatzenbuehler, M. L., Rendina, H. J., Safren, S. A., \& Parsons, J. T. (2015). LGB-affirmative cognitive-behavioral therapy for young adult gay and bisexual men: A randomized controlled trial of a transdiagnostic minority stress approach. Journal of Consulting and Clinical Psychology, 83(5), 875-886. https://doi.org/10.1037/ccp0000037

Reinert, D. F., \& Allen, J. P. (2002). The alcohol use disorders identification test (AUDIT): a review of recent research. Alcoholism: Clinical and Experimental Research, 26, 272-279.

Renner, L. M., \& Whitney, S. D. (2012). Risk factors for unidirectional and bidirectional intimate partner violence among young adults. Child Abuse and Neglect. https://doi.org/10.1016/j.chiabu.2011.07.007

Reuter, T. R., Newcomb, M. E., Whitton, S. W., \& Mustanski, B. (2017). Intimate partner violence victimization in LGBT young adults: Demographic differences and associations with health behaviors. Psychology of Violence, 7(1), 101-109. https://doi.org/10.1037/vio0000031 
Rogers, A. H., Seager, I., Haines, N., Hahn, H., Aldao, A., \& Ahn, W. Y. (2017). The indirect effect of emotion regulation on minority stress and problematic substance use in lesbian, gay, and bisexual individuals. Frontiers in Psychology. https://doi.org/10.3389/fpsyg.2017.01881

Saunders, J. B., Aasland, O. G., Babor, T. F., de la Fuente, J. R., \& Grant, M. (1993). Development of the Alcohol Use Disorders Identification Test (AUDIT): WHO Collaborative Project on Early Detection of Persons with Harmful Alcohol Consumption--II. Addiction (Abingdon, England). https://doi.org/10.1111/j.13600443.1993.tb02093.x

Spitzer, R. L., Kroenke, K., Williams, J. B. W., \& Löwe, B. (2006). A Brief Measure for Assessing Generalized Anxiety Disorder. Archives of Internal Medicine. https://doi.org/10.1001/archinte.166.10.1092

Sterzing, P. R., Gartner, R. E., Goldbach, J. T., McGeough, B. L., Ratliff, G. A., \& Johnson, K. C. (2017). Polyvictimization Prevalence Rates for Sexual and Gender Minority Adolescents: Breaking Down the Silos of Victimization Research. Psychology of Violence. https://doi.org/10.1037/vio0000123

Sterzing, P. R., Hong, J. S., Gartner, R. E., \& Auslander, W. F. (2016). Child Maltreatment and Bullying Victimization Among a Community-Based Sample of Sexual Minority Youth: The Meditating Role of Psychological Distress. Journal of Child \& Adolescent Trauma, 9(4), 283-293. https://doi.org/10.1007/s40653-0160101-4

Straus, M. A., \& Douglas, E. M. (2004). A Short Form of the Revised Conflict Tactics Scales, and Typologies for Severity and Mutuality. Violence and Victims. https://doi.org/10.1891/088667004780927800

Talley, A. E., Gilbert, P. A., Mitchell, J., Goldbach, J., Kaysen, D., States, U., ... Behaviors, R. (2016). Addressing gaps on risk and resilience factors for alcohol use outcomes in sexual and gender minority populations. Drug Alcohol Review, 35(4), 484-493. https://doi.org/10.1111/dar.12387

Tourangeau, R., \& Smith, T. W. (1996). Asking Sensitive Questions: The Impact of Data Collection Mode, Question Format, and Question Context. Public Opinion Quarterly. https://doi.org/10.1086/297751

Walters, K., Christakis, D. A., \& Wright, D. R. (2018). Are mechanical turk worker samples representative of health status and health behaviors in the U.S.? PlosOne. doi. org/10.1371/journal.pone.0198835

Walters, M. L., Chen, J., \& Breiding, M. J. (2013). The National Intimate Partner and Sexual Violence Survey 2010 Findings on Victimization by Sexual Orientation. National Intimate, 1-48. https://doi.org/10.1037/e541522013-001

Watkins, L. E., Maldonado, R. C., \& DiLillo, D. (2016). The Cyber Aggression in Relationships Scale: A New Multidimensional Measure of Technology-Based Intimate Partner Aggression. Assessment, 19, 608-626. https://doi.org/10.1177/1073191116665696

Wolford-Clevenger, C., Zapor, H., Brasfield, H., Febres, J., Elmquist, J., Brem, M., ... Stuart, G. L. (2016). An examination of the partner cyber abuse questionnaire in a college student sample. Psychology of Violence. https://doi.org/10.1037/a0039442

Wright, M. F. (2014). Cyber Aggression Within Adolescents' Romantic Relationships: Linkages to Parental and Partner Attachment. Journal of Youth and Adolescence. 
https://doi.org/10.1007/s10964-014-0147-2

Zweig, J. M., Lachman, P., Yahner, J., \& Dank, M. (2014). Correlates of Cyber Dating Abuse Among Teens. Journal of Youth and Adolescence. https://doi.org/10.1007/s10964-013-0047-x 
Table 1

Distribution of Race-ethnic Minority Status and CAN and IPV types in LGB emerging adults

\begin{tabular}{|c|c|c|c|c|c|}
\hline & $\begin{array}{l}\text { Lesbian } \\
(n=46)\end{array}$ & $\begin{array}{c}\text { Gay } \\
(n=71)\end{array}$ & $\begin{array}{c}\text { Bisexual } \\
\text { women } \\
(n=119)\end{array}$ & $\begin{array}{c}\text { Bisexual } \\
\text { men } \\
(n=41)\end{array}$ & $\begin{array}{c}\text { Gender } \\
\text { diverse/ } \\
\text { expansive } \\
(n=11)\end{array}$ \\
\hline & \multicolumn{4}{|c|}{$n$ (\% of the total population) } & \\
\hline Race-ethnic Minority & $21(7.3)$ & $31(10.8)$ & $50(17.4)$ & $20(6.9)$ & $3(1.0)$ \\
\hline \multicolumn{6}{|l|}{ Childhood Maltreatment } \\
\hline Emotional Abuse & $18(6.3)$ & $31(10.8)$ & $77(26.7)$ & $15(5.2)$ & $10(3.5)$ \\
\hline Physical Abuse & $7(2.4)$ & $32(11.1)$ & $52(18.1)$ & $13(4.5)$ & $6(2.1)$ \\
\hline Sexual Abuse & $15(5.2)$ & $27(9.4)$ & $61(21.2)$ & $16(5.6)$ & $5(1.7)$ \\
\hline Emotional Neglect & $30(10.4)$ & $48(16.7)$ & $86(29.9)$ & $28(9.7)$ & $9(3.1)$ \\
\hline Physical Neglect & $22(7.6)$ & $42(14.6)$ & $70(24.3)$ & $24(8.3)$ & $9(3.1)$ \\
\hline \multicolumn{6}{|l|}{ Adulthood IPV } \\
\hline Physical Assault & $10(3.5)$ & $20(6.9)$ & $18(6.3)$ & $15(5.2)$ & $1(.003)$ \\
\hline Sexual Assault & $9(3.1)$ & $16(5.6)$ & $13(4.5)$ & $8(2.8)$ & $1(.003)$ \\
\hline Psychological Abuse & $10(3.5)$ & $20(6.9)$ & $18(6.3)$ & $15(5.2)$ & $1(.003)$ \\
\hline Injury from IPV & $7(2.4)$ & $18(6.3)$ & $11(3.8)$ & $10(3.5)$ & $0(0)$ \\
\hline Sexual Cyber IPV & $15(5.2)$ & $29(10.1)$ & $34(11.8)$ & $17(5.9)$ & $3(1.0)$ \\
\hline Psychological Cyber IPV & $25(8.7)$ & $43(14.9)$ & $61(21.2)$ & $20(6.9)$ & $4(1.4)$ \\
\hline Stalking Cyber IPV & $23(8.0)$ & $39(13.5)$ & $65(22.6)$ & $18(6.3)$ & $5(1.7)$ \\
\hline
\end{tabular}

Note. IPV = Intimate partner violence victimization. Race-ethnic minority includes people of color and white hispanic individuals 
Table 2

Fit Indices for the Latent Class Models with Two to Six Classes Based on Childhood Maltreatment and Intimate Partner Victimization in Lesbian, Gay, and Bisexual Individuals

\begin{tabular}{|c|c|c|c|c|c|c|}
\hline $\begin{array}{l}\text { Number of } \\
\text { classes }\end{array}$ & $\begin{array}{l}\text { LMR } \\
\text { ( } p \text { value) }\end{array}$ & $\begin{array}{l}\text { BLRT } \\
(p \text { value })\end{array}$ & Entropy & AIC & BIC & SSABIC \\
\hline 2 & $\begin{array}{l}387.01 \\
(.002)\end{array}$ & $\begin{array}{l}-2071.46 \\
(.001)\end{array}$ & .99 & 3800.65 & 3892.23 & 3812.95 \\
\hline 3 & $\begin{array}{l}352.01 \\
(.001)\end{array}$ & $\begin{array}{l}-1875.33 \\
(.001)\end{array}$ & .91 & 3469.86 & 3602.05 & 3488.55 \\
\hline 4 & $\begin{array}{l}117.66 \\
(.02)\end{array}$ & $\begin{array}{l}-1696.93 \\
(.001)\end{array}$ & .91 & 3376.60 & 3563.41 & 3401.68 \\
\hline 5 & $\begin{array}{l}82.62 \\
(.02)\end{array}$ & $\begin{array}{l}-1818.31 \\
(.001)\end{array}$ & .89 & 3318.86 & 3553.29 & 3350.33 \\
\hline 6 & $\begin{array}{l}62.56 \\
(.13)\end{array}$ & $\begin{array}{l}-1595.43 \\
(.001)\end{array}$ & .89 & 3281.46 & 3563.51 & 3319.33 \\
\hline
\end{tabular}

Note. LMR $=$ Lo-Mendell-Rubin test. BLRT $=$ Bootstrapped likelihood ratio test. $\mathrm{BIC}=$ Bayesian information criterion. SSABIC $=$ Sample size adjusted Bayesian information criterion. 
Table 3

Probabilities of LGB Adults across the Fives Classes of CAN and IPV types

\begin{tabular}{|c|c|c|c|c|c|}
\hline Victimization & Class 1 & Class 2 & Class 3 & Class 4 & Class 5 \\
\hline \multicolumn{6}{|l|}{ Childhood Maltreatment } \\
\hline Emotional Abuse & .965 & .91 & .339 & .198 & .098 \\
\hline Physical Abuse & .911 & .531 & .175 & .257 & .048 \\
\hline Sexual Abuse & .973 & .619 & .175 & .257 & .101 \\
\hline Emotional Neglect & .963 & .877 & .562 & .732 & .408 \\
\hline Physical Neglect & .984 & .722 & .323 & .583 & .318 \\
\hline \multicolumn{6}{|l|}{ Adulthood IPV } \\
\hline Physical Assault & .043 & .028 & .099 & 1.00 & 0 \\
\hline Sexual Assault & .153 & .024 & 0 & 1.00 & .043 \\
\hline Psychological Abuse & .122 & .127 & .141 & .971 & .111 \\
\hline Injury from IPV & .125 & .028 & .089 & .971 & 0 \\
\hline Sexual Cyber IPV & .896 & .068 & .545 & .256 & .105 \\
\hline Psychological Cyber IPV & .963 & .301 & 1.00 & .375 & .202 \\
\hline Stalking Cyber IPV & 1.00 & .307 & 1.00 & .435 & .104 \\
\hline
\end{tabular}

Note: Class $1=$ High victimization $(\mathrm{HV} ; n=55)$. Class $2=$ Childhood emotional abuse and neglect (CEAN; $n=73$ ). Class $3=$ Cybervictimization (CYBV; $n=53)$. Class $4=$ Adult face-toface intimate partner victimization (IPV; $n=34$ ). Class $5=$ Low victimization (LV; $n=73$ ). IPV - Intimate partner violence victimization. 
Table 4

Multinomial Logistic Regression using the 3-step Procedure for Sexual Orientation and Raceethnicity as Predictors of the Five Latent Classes

\begin{tabular}{|c|c|c|c|}
\hline & Estimate & SE & z-test \\
\hline \multicolumn{4}{|l|}{ Class 1 vs. Class 5} \\
\hline Gay men (vs. bisexual men) & .27 & .48 & .57 \\
\hline Lesbian women (vs. bisexual women) & -.75 & .59 & -1.27 \\
\hline Bisexual men (vs. bisexual women) & -.57 & & -.97 \\
\hline White Non-Hispanic (vs. REM) & -1.03 & 0.39 & $-2.64 * *$ \\
\hline \multicolumn{4}{|l|}{ Class 2 vs. Class 5} \\
\hline Gay men (vs. bisexual men) & -1.98 & .64 & $-3.10 * *$ \\
\hline Lesbian women (vs. bisexual women) & -1.95 & .65 & $-2.98 * *$ \\
\hline Bisexual men (vs. bisexual women) & -2.66 & .93 & $-2.86 * *$ \\
\hline White Non-Hispanic (vs. REM) & .03 & .45 & .08 \\
\hline \multicolumn{4}{|l|}{ Class 3 vs. Class 5} \\
\hline Gay men (vs. bisexual men) & -.36 & .52 & -.70 \\
\hline Lesbian women (vs. bisexual women) & -.62 & .57 & -1.10 \\
\hline Bisexual men (vs. bisexual women) & -.68 & .58 & -1.17 \\
\hline White Non-Hispanic (vs. REM) & -.22 & .42 & -.53 \\
\hline \multicolumn{4}{|l|}{ Class 4 vs. Class 5} \\
\hline Gay men (vs. bisexual men) & .47 & .56 & .84 \\
\hline Lesbian women (vs. bisexual women) & .03 & .63 & .04 \\
\hline Bisexual men (vs. bisexual women) & -.09 & .64 & .14 \\
\hline White Non-Hispanic (vs. REM) & -.55 & .43 & -1.29 \\
\hline
\end{tabular}

Note. REM = racial-ethnic minorities, including White Hispanic individuals. In parentheses is the reference group.

$* p<.05$

$* * p<.01$ 
Table 5

Mean and Standard Error across the Latent Classes on Emotion Dysregulation, Depression, Anxiety, and Alcohol use

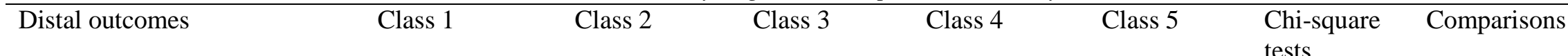

\begin{tabular}{|c|c|c|c|c|c|c|c|}
\hline Emotion dysregulation & \multicolumn{5}{|c|}{ Mean (SE) } & & \\
\hline Depression symptoms & $\begin{array}{l}13.46 \\
(0.78)\end{array}$ & $\begin{array}{l}12.49 \\
(0.92)\end{array}$ & $\begin{array}{l}9.23 \\
(1.19)\end{array}$ & $\begin{array}{l}4.71 \\
(1.16)\end{array}$ & $\begin{array}{l}1.53 \\
(0.34)\end{array}$ & $332.19 * * *$ & $1,2>3>4>5$ \\
\hline Anxiety symptoms & $\begin{array}{l}9.99 \\
(0.68)\end{array}$ & $\begin{array}{l}11.14 \\
(0.79)\end{array}$ & $\begin{array}{l}7.10 \\
(0.98)\end{array}$ & $\begin{array}{l}4.32 \\
(1.02)\end{array}$ & $\begin{array}{l}1.81 \\
(0.62)\end{array}$ & $125.64 * * *$ & $1,2>3>4>5$ \\
\hline
\end{tabular}

Note: Class $1=$ High victimization (HV; $n=55)$. Class $2=$ Childhood emotional abuse and neglect (CEAN; $n=73)$. Class $3=$ Cybervictimization (CYBV; $n=53)$. Class $4=$ Adult face-to-face intimate partner victimization (IPV; $n=34)$. Class $5=$ Low victimization $(\mathrm{LV} ; n=73)$. $* * * p<.001$. 